\title{
O orçamento de defesa dos EUA: racionalidade $X$ pressões domésticas
}

\author{
The American defense budget: \\ rationality $X$ domestic pressures
}

http://dx.doi.org/10.1590/0034-7329201400304

JULIANO DA SILVA CORTINHAS*

Rev. Bras. Polít. Int. 57 (2): 58-81 [2014]

\section{Introdução}

Com o fim da ordem sistêmica bipolar da Guerra Fria, o governo estadunidense começou a discutir qual seria o papel do país na Nova Ordem Internacional, termo utilizado pelo então Presidente George H. W. Bush para descrever a estrutura internacional que se formava. Apesar de alguns analistas defenderem que os Estados Unidos deveriam construir uma "era unipolar" (Krauthammer 1990/1991) com base na força, a Administração Bush (1989-1992) decidiu que o país deveria reduzir seus gastos militares, transferindo a prioridade do orçamento para o reequilíbrio da economia nacional, que vinha passando por uma profunda crise orçamentária. O Presidente defendia que, em um contexto de interdependência complexa, as responsabilidades de estabilização do sistema poderiam ser divididas.

Apesar dos esforços de Bush, o Legislativo estadunidense decidiu manter a maioria dos programas de armamentos que o Presidente pretendia cancelar, impedindo uma redução substancial do orçamento de defesa estadunidense.

Este artigo objetiva, por meio da análise dos processos decisórios do orçamento de defesa dos Estados Unidos durante o primeiro governo de Reagan (1981-1984) e a Administração Bush (1989-1992), compreender as razões para a histórica tendência de estabilização dos gastos com defesa dos EUA, que, desde o final da Guerra do Vietnã, em torno de 4,6\% do produto interno bruto daquele país ${ }^{1}$.

* Instituto Pandiá Calógeras, Ministério da Defesa, Brasília, DF, Brasil (jcortinhas@gmail.com).

1 Entre 1975 e 2012, percebe-se diferenças importantes entre os orçamentos de Reagan, em que o percentual de gastos com defesa chegou a 6\% do PIB e a Administração Clinton, em que os valores chegaram a um mínimo de $3 \%$. Mesmo assim, períodos de declínio do orçamento de defesa são rapidamente seguidos por novos aumentos. Dados disponíveis em <http://www.whitehouse.gov/sites/default/files/omb/budget/fy2009/pdf/hist.pdf>. Acesso em: 10 jan. 2014. 
As características estruturais em que o orçamento é discutido e as preferências dos agentes que participam de seu processo de elaboração contribuem para que seja evidente uma tendência de manutenção dos gastos. Períodos de declínio do orçamento militar são rapidamente seguidos por aumentos dessas despesas ${ }^{2}$. Diferentemente do que prevê a maioria das teorias de Relaçôes Internacionais, as razões que explicam esse fenômeno estão, eminentemente, no âmbito interno da política daquele país ${ }^{3}$. Por isso, as teorias sistêmicas que explicam os gastos com defesa, como as desenvolvidas por Kenneth Waltz e Susan Strange ${ }^{5}$, precisam ser complementadas. Para tanto, o artigo propõe a utilização dos modelos de Graham Allison $^{6}$, que, apesar de apresentarem contribuições relevantes, também possuem limitações, pois privilegiam a simplificação metodológica.

Com o intuito de minimizar essa dificuldade, duas adaptações são propostas aos modelos conceituais de Allison (Allison e Zelikow 1999). A primeira é tratálos como parte de um continuum de distribuição de poder entre os agentes do processo decisório. O modelo I está no primeiro extremo desse continuum, em que o poder é concentrado nas mãos de um só agente, e o modelo III está no extremo contrário, marcado por uma extensa divisão do poder de decisão entre agentes que buscam influenciar o processo decisório e os tomadores de decisão do governo. A principal contribuição trazida pelo continuum é a noção de que os modelos de Allison são complementares, e não contraditórios. Entende-se, portanto, que a análise do orçamento de defesa dos EUA pode ser realizada pela associação entre os tipos ideais do autor, pois as decisões orçamentárias são extremamente complexas e possuem características que variam ao longo dos anos, podendo se aproximar mais de um ou de outro extremo ${ }^{7}$.

2 Enquanto Reagan assumiu a presidência em um contexto de acirramento das rivalidades com a URSS e possuía uma ampla base de apoio no Congresso, Bush iniciou sua Administração sem um momento de declínio da URSS, o que dificultou a construção de consensos domesticamente. A análise desses períodos, bastante distintos, permitirá demonstrar as diferenças entre um ambiente de prevalência do Executivo e outro, de ascensão do Legislativo no processo de discussôes orçamentárias.

3 Desse modo, a presunção de racionalidade das teses sistêmicas não se mostra adequada para explicar a questão.

4 Para Waltz (2002), os Estados tendem a maximizar seus gastos com defesa em ambientes menos estáveis. Como o autor defende que o sistema mais estável é o bipolar, o fim da Guerra Fria levaria a um aumento dos gastos estadunidenses. Isso, porém, não ocorreu.

5 Strange (1999) argumenta que o aumento das ameaças percebidas levaria a uma aceleração dos gastos com defesa. Se a relação proposta pela autora realmente existisse, portanto, o encerramento da Guerra Fria permitiria que os estadunidenses reduzissem seu orçamento de defesa. A hipótese de Strange se comprova apenas parcialmente, pois apesar de constantemente haver um aumento dos gastos em situaçóes de conflito armado por que passaram os EUA, não parece haver uma redução considerável dessas despesas quando as ameaças são minimizadas, ao menos desde o fim da Guerra do Vietnã. Além disso, a redução dos custos após os conflitos armados está mais associada à desmobilização das Forças Armadas do que a uma redução da percepção de ameaças.

6 Ao final da década de 60, Allison (1969) enumerou três modelos conceituais para explicar o processo decisório do governo dos EUA durante a Crise dos Mísseis. Os tipos ideais desenvolvidos pelo autor são conhecidos como racional (ou modelo I), organizacional (modelo II) e de política burocrática (modelo III). Diversos autores apresentaram críticas e propuseram evoluçôes aos modelos originais de Allison, mas eles continuam sendo paradigmáticos na análise de processos decisórios.

7 Essa aplicação de diferentes modelos para explicar os processos decisórios de forma concomitante está de acordo com a própria visão de Allison acerca da aplicação dos modelos (ALLISON, 1969, p. 716). 
A segunda adaptação é a sua associação aos conceitos do debate agenteestrutura, minimizando o individualismo excessivo da proposta de Allison ${ }^{8}$.

Essas adaptaçôes permitirão ao leitor compreender que os movimentos de aumento e diminuição dos gastos com defesa dos EUA tendem a ser influenciados por forças estruturais (sistêmicas e domésticas) e agenciais (principalmente domésticas). Acredita-se que, em grande medida, a análise formulada neste artigo poderá auxiliar no exame mais geral sobre as discussões do orçamento de defesa estadunidense, pois mesmo em momentos em que o Executivo pretende realizar cortes nos gastos, há uma série de pressões que atuam na direção contrária, como parece estar ocorrendo na Administração Obama.

\section{A análise do orçamento de defesa dos EUA pela associação dos modelos de Allison com o debate agente-estrutura em Relações Internacionais}

O debate agente-estrutura vem sendo desenvolvido, nas Relações Internacionais, principalmente pela Teoria Construtivista e, mais modernamente, pelo Realismo Científico. A proposta deste artigo se aproxima da segunda visão, pois leva em consideração a abordagem de Wight (2006), que parte da noção de que toda vida social é estruturada a partir de quatro faces de um mesmo cubo social (Wight 2006, 174). A primeira tem natureza material, marcada pelos recursos ou atributos físicos das unidades em interação, que são determinados tanto por suas características individuais quanto pelas estruturas em que atuam; a segunda é denominada de ações inter-intrassubjetivas, composta pelas regras, normas, crenças e instituiçôes que constituem a vida social; a terceira se refere às relaçôes sociais, que determinam a composição da estrutura e também o posicionamento dos agentes; a última face é a da subjetividade do agente.

Para que sejam compreendidas as relações dos agentes com as estruturas de que fazem parte, as quatro faces devem estar contempladas na análise. Portanto, o exame do orçamento de defesa dos EUA precisa considerá-las na análise da estrutura e do papel dos agentes que dele participam. Isso será realizado pela exposição das variáveis que estão relacionadas com os agentes que atuam no processo decisório e, a seguir, pelo exame das variáveis estruturais que o caracterizam.

O papel dos agentes deve ser compreendido a partir do que Wight denomina de três níveis de agência ${ }^{9}$. São quatro os principais agentes que atuam no processo decisório do orçamento de defesa dos EUA: os membros do Executivo e os membros

8 Como os modelos de Allison já são amplamente conhecidos, o artigo não pretende fazer uma revisão das conclusões do autor. $\mathrm{O}$ foco do debate teórico aqui proposto estará na discussão sobre o debate agente-estrutura e em como seus conceitos podem ser associados aos de Allison.

9 O nível de agência1 está relacionado com a "liberdade de subjetividade", o nível agência2 refere-se à forma pela qual a agência1 se torna um agente do sistema sociocultural em que nasce e se desenvolve, já que os indivíduos se tornam agentes de partes (grupos ou coletividades) do sistema sociocultural em que vivem. A agência3 se refere ao que Wight denomina de "lugares de práticas posicionadas" que os agentes1 habitam, ou seja, reflete os “papéis” que os agentes1 desempenham para a agência2 (WIGHT, 2006, p. 213). 
do Legislativo são tomadores de decisão, enquanto os militares e grupos de interesse agem com o objetivo de influenciar seu resultado ${ }^{10}$.

A partir do conceito de agêncial, pode-se afirmar que o indivíduo mais influente no processo decisório é o Presidente. Por isso, suas características pessoais, como a "personalidade" e a "popularidade", são importantes. Além dessas variáveis, o exame da ideologia dos tomadores de decisão do processo (Presidente e legisladores ${ }^{11}$ também é relevante para esse nível de agência.

Com relação ao nível de agência2, as variáveis utilizadas são o partido político do agente e sua representatividade eleitoral ${ }^{12}$.

Apesar da importância desses dois níveis, na análise dos orçamentos de defesa dos EUA, o nível de agência3, que se refere ao papel que os agentes ocupam no processo decisório, parece ser mais relevante. Isso decorre das diferenças existentes nas condiçôes de representatividade dos membros do Executivo e do Legislativo. Os primeiros representam uma parcela muito maior do eleitorado que os congressistas, o que torna os legisladores mais vulneráveis aos grupos de interesse (lobbies) de seus distritos de origem (Milner 1997; Shepsle e Weingast 1984). Dessa forma, a emergência do Legislativo no processo decisório tende a privilegiar grupos específicos.

Além do Presidente e dos legisladores, mais dois agentes participam do processo decisório buscando influenciá-lo. Os membros das Forças Armadas concentram sua pressão sobre o Executivo, procurando aumentar os gastos e atuando conjuntamente, de modo a não estabelecer uma concorrência entre si, o que prejudicaria seus interesses no longo prazo (Stubbing 1984; Smith 1996).

$10 \mathrm{O}$ papel da mídia não será analisado neste artigo. Apesar de que o posicionamento dos veículos de comunicação pode ser considerado muito relevante em temas relacionados com a agenda doméstica, como propõem as teorias pluralistas, a influência da mídia sobre as escolhas dos tomadores de decisão acerca do orçamento de defesa não parece ser tão relevante. Nessa temática específica, a posição da teoria elitista, que percebe a mídia como um instrumento das elites financeiras (e, portanto, dos grupos de interesse) para convencer a opinião pública de que certos investimentos são necessários, é mais adequada (Wittkopf e McCormick 2004). A importância da mídia tende a emergir, nas questóes relacionadas com o orçamento de defesa, em momentos muito específicos, principalmente quando há fortes acréscimos dos gastos, como no pós-11 de setembro, por exemplo (Jentleson 2010, 58-62). Nesses momentos, a mídia pode moldar a opinião pública. Mesmo assim, a influência dos meios de comunicação sobre o resultado final dos debates orçamentários é apenas indireta.

11 A caracterização da ideologia dos membros das Casas e dos Presidentes analisados foi realizada com base nos números fornecidos pelo think tank "Americans for Democratic Action" e na metodologia proposta por McCormick e Wittkopf (1990, p. 1083). Neste artigo, não foram feitas observações muito abrangentes sobre a ideologia dos legisladores e, para a mensuração de sua ideologia, considerou-se a média dos componentes do Congresso. Deve-se destacar, apenas, que na Administração Reagan a ideologia do Legislativo, principalmente nos dois primeiros anos de mandato, era bastante conservadora, ou seja, muito próxima da ideologia do Presidente. Já nos dois últimos anos de Reagan e nos quatro anos de Bush, havia grandes diferenças entre a ideologia do Presidente e do Legislativo, sendo mais difícil a articulação da aprovação das preferências do Chefe do Executivo pelo Congresso.

12 A consideração desse nível de agência não permite aproximar os processos decisórios de um ou outro modelo de Allison. É relevante, porém, para compreender o resultado do processo orçamentário e do posicionamento pessoal dos agentes. Os tomadores de decisão ligados ao Partido Republicano têm uma tendência de aprovar maiores gastos com defesa (COBB, 1969) que os Democratas. A representatividade eleitoral é relevante porque tomadores de decisão pertencentes a distritos eleitorais com grandes investimentos em defesa tendem a apoiar maiores gastos. 
Já os grupos de interesse, no sistema político dos EUA, têm grande intensidade (Goldstein 1999) e capacidade organizacional (Olson 1999; Smith 1996; Domke 1984) e, por isso, têm papel fundamental nos processos decisórios.

Além de caracterizar os agentes que atuam nos processos de elaboração do orçamento de defesa dos EUA, é importante observar como a estrutura em que se inserem influencia seu posicionamento. Para tanto, o exame de dois conjuntos de variáveis é relevante: as normas que regulam o comportamento dos agentes e as condições estruturais que determinam o equilíbrio de poder entre eles.

A análise das normas que regulam a construção do orçamento de defesa dos EUA demonstra que há uma extensa divisão de funçõos na sua elaboração. O Executivo tem o poder de agenda, o que lhe dá uma grande vantagem (Barrett e Eshbaugh-Soha 2007; Allison e Zelikow 1999, Bernstein 2000), pois pode moldar as discussões no Legislativo, criando padrões e estabelecendo os programas que os congressistas irão debater. Os legisladores, contudo, têm o poder de decisão final sobre o orçamento.

A lei que regula o processo orçamentário é a Lei do Orçamento de 1974, aprovada em um momento de grande prevalência institucional do Legislativo sobre o Executivo ${ }^{13}$. Por isso, a norma atribui extensas vantagens ao Congresso no processo decisório. Isso, porém, não é suficiente para que os posicionamentos dos legisladores prevaleçam, o que somente ocorre se outras variáveis estruturais estiverem combinadas de modo a privilegiar o Legislativo.

De acordo com a hipótese deste artigo, as variáveis que afetam o equilíbrio de poder entre Executivo e Legislativo e, portanto, influenciam as características do processo orçamentário, são as seguintes:

- Estrutura internacional - A estrutura internacional é uma das duas macroestruturas que interferem no montante de gastos com defesa realizados pelos Estados Unidos. Como indicam diversos autores (Strange 1999; Berry e Lowery 1990, 688; McCormick et al. 1997, 135), a demanda por esses gastos aumenta em períodos de maior ameaça internacional e em situações de conflito militar, pois, nesses cenários específicos, o equilíbrio das contas orçamentárias fica em segundo plano. Além disso, nessas ocasiōes, a necessidade de decisões rápidas e eficientes privilegia o papel do Executivo. A diminuição das ameaças internacionais, por outro lado, abre espaço para a prevalência do Congresso, pois a preocupação com a eficiência dos gastos diminui (Wittkopf e McCormick 1998, 443). Vê-se, portanto, que variáveis sistêmicas interferem diretamente no equilíbrio de poder entre Legislativo e Executivo.

13 Essa prevalência foi decorrente de vários eventos internacionais e domésticos, como a má gestão da Guerra do Vietnã, a primeira crise do petróleo e a crise política decorrente do escândalo de Watergate. Percebendo um contexto favorável, o Congresso aprovou a Lei de 1974, que criou várias ferramentas para que o Legislativo pudesse se impor sobre o Presidente, como a exigência da elaboração de um orçamento próprio do Congresso, que pode ser muito divergente da proposta do Executivo. 
- Divisão partidária do governo - ocorre quando o Presidente é de um partido e a maioria do Legislativo pertence ao outro. Sem um amplo apoio do Congresso, um Presidente não tem condiçôes de aprovar as políticas de seu interesse ou de promover grandes alterações orçamentárias ${ }^{14}$. Essa variável está relacionada com a anterior, pois, como observa Mayhew (1991, 195-196), em situações de grandes ameaças externas, a divisão partidária diminui, já que os legisladores se afastam das disputas partidárias, e passa a existir uma grande tendência de apoio ao Presidente.

- Estado da Economia - as diferenças estruturais entre um ambiente de prosperidade econômica e um ambiente em que há déficits orçamentários e pressões inflacionárias e empregatícias são profundas. Se o orçamento for superavitário, o Presidente tem mais liberdade para exigir do Congresso políticas que o satisfaçam. Além disso, a pressão doméstica sobre os congressistas tende a diminuir, deixando-os mais livres para atender às demandas de um Presidente que vem, ao menos teoricamente, construindo políticas econômicas equilibradas. Ao contrário, se o orçamento enviado pelo Presidente é deficitário, a pressão dos grupos de interesse sobre os congressistas aumenta, pois nenhum ator societal está interessado em perder seus recursos. Como a margem dos legisladores para atender os grupos específicos será menor, tenderão a cortar gastos que considerem desnecessários, mesmo que tenham sido requeridos pelo Presidente. Nesse cenário, cortes de programas de armamentos, que representariam a perda de empregos importantes em uma indústria politicamente forte, serão dificilmente realizados. Assim, quando a economia vai mal, o poder tende a fluir para o Legislativo, que terá maior autonomia para analisar os pedidos orçamentários do Executivo. Neste artigo, o estado da economia dos EUA é analisado a partir de indicadores específicos: crescimento da economia, taxa de juros, inflação, desemprego, índice de miséria e déficit orçamentário.

- Opinião pública - a importância da opinião pública para a tomada de decisão acerca do orçamento de defesa dos EUA é inconstante, sendo sua influência mais relevante e mais claramente perceptível em momentos de graves crises internacionais ou quando a economia está em situação precária. O crescimento das ameaças externas, por exemplo, cria um ambiente de forte nacionalismo e um maior apoio aos gastos ${ }^{15}$. Ao contrário, crises econômicas aumentam a pressão popular pelo corte de gastos militares.

\footnotetext{
14 As análises que tratam do apoio bipartidário às demandas presidenciais nos EUA identificam que, quando o Presidente se posiciona claramente com relação a um tema, a diferença de apoio, no Congresso, de membros do seu e do outro partido varia em cerca de 25\% (EDWARDS III; WAYNE, 1994, p. 298-300).

15 O efeito é conhecido como "rally around the flag" (Oneal e Bryan 1985; Baum 2002). Em momentos de ameaças evidentes, a popularidade do Presidente tende a bater recordes, como ocorreu com George Bush depois da Guerra do Golfo, em 1991 (Edwards III e Wayne 1994, 330; Thrall e Cramer 2009).
} 
- Ciclo Eleitoral - no primeiro ano de governo, os Presidentes tendem a ter um maior apoio da opinião pública e do eleitorado, sendo esse período chamado de lua-de-mel do Presidente. Nesses momentos, grandes alterações na política orçamentária são mais comuns (Barrett e Eshbaugh-Soha 2007; Edwards III e Wayne 1994; Mayer 1995). No último ano dos mandatos, também o efeito do ciclo eleitoral é evidente, pois nenhum tomador de decisão está disposto a cortar gastos que possam gerar desemprego em períodos próximos de uma nova eleição.

- Distribuição das informações - a distribuição das informações é uma variável relevante para a análise de um processo decisório, pois os agentes que possuem informaçóes mais adequadas tendem a ser beneficiados (Milner 1997). A princípio, o Presidente, pela sua estrutura de assessores, tem mais condiçōes de reunir melhores informações. Por outro lado, os grupos de interesse das indústrias de defesa cumprem o relevante papel de suprir informações aos legisladores. Além disso, a Lei do Orçamento de 1974 criou o Escritório de Orçamento do Congresso, que diminuiu a lacuna informacional entre o Executivo e o Legislativo.

Somadas a essas variáveis estruturais, características específicas dos agentes anteriormente citados têm influência sobre as decisōes orçamentárias:

- Personalidade do Presidente - a personalidade do Chefe do Executivo influencia seu posicionamento sobre o papel dos EUA no mundo e sobre a necessidade de investimentos em defesa. A variável será mensurada de acordo com Barber (1992), que desenvolve quatro tipos ideais de caráter presidencial ${ }^{16}$, associando-os a cada Presidente que examina.

- Popularidade do Presidente - um Presidente popular tem mais facilidades nas relações com o Congresso. Dificilmente o Congresso irá contrariar um Presidente que se posicione claramente acerca de um tema e seja popular (Edwards III e Wayne 1994; Andrade e Young 1996).

- Ideologia - este artigo utiliza a categorização proposta por McCormick e Wittkopf (1990), que classificam os agentes políticos dos EUA entre conservadores, moderados e liberais. A consideração da ideologia dos agentes é importante em dois aspectos: primeiramente, porque se o

16 O primeiro é o Presidente ativo e positivo, que exige de seus assessores um padrão de qualidade elevado em suas respostas, enquanto busca construir um ambiente produtivo e positivo de trabalho. George Bush se encaixa nesse perfil. A segunda categoria é o Presidente ativo e negativo, que também possui uma grande capacidade de trabalho, mas não sente prazer no exercício da função. $\mathrm{O}$ terceiro tipo, em que Barber insere Reagan, é o Presidente passivo-positivo, que busca criar consensos entre os membros de sua equipe, mas se sente pessimista com relação a si mesmo e deixa a construção de novas políticas a cargo de seus assessores. Por fim, o Presidente passivo-negativo tende a ter problemas no cumprimento de sua função e dificuldades nas relações com seus assessores. 
Presidente e a média dos congressistas possuem ideologia semelhante, a decisão tende a favorecer o primeiro, que formula a agenda. Além disso, se ambos tiverem ideologias conservadoras, como aconteceu durante a gestão de Reagan, ao menos nos dois primeiros anos do mandato, a tendência de aumento dos gastos com defesa tende a se concretizar.

- Intensidade dos lobbies - quando são politicamente poderosos, os grupos de pressão de uma determinada indústria tendem a ter grande capacidade de influência sobre uma decisão (Goldstein 1999) ${ }^{17}$. Isso claramente ocorre nos debates do orçamento de defesa, pois o lobby das indústrias de armamentos é considerado um dos mais fortes do cenário político estadunidense (Smith 1996; Gholz e Sapolski 1999-2000; Domke 1984). A relação simbiótica entre os grupos de pressão da indústria de defesa, os congressistas e os membros das Forças Armadas, conhecida como Triângulo de Ferro (Smith 1996), é o principal instrumento político desenvolvido pela indústria, cuja força pode ser medida pela sua riqueza e pelos resultados financeiros positivos que vêm obtendo ao longo dos anos (Cobb 1969).

Esse conjunto de variáveis aponta os cenários decisórios em que existe uma prevalência do Executivo ou, ao contrário, em que há a ascensão dos legisladores. No primeiro caso, a tendência é de uma decisão que se aproxime mais do modelo I (racional) de Allison, pois o Presidente está mais isolado das pressões específicas dos grupos de interesse e é o responsável direto pela criação de políticas de defesa que aumentem o nível de preparação dos Estados Unidos contra possíveis ameaças. A ascensão do Congresso no processo de elaboração do orçamento de defesa, por outro lado, aproxima a decisão do previsto pelo modelo III (política governamental) de Allison, pois há a emergência de diversos atores societais no processo.

A seguir, propõe-se um quadro (Tabela 1) em que as variáveis estruturais e agenciais discutidas neste artigo são relacionadas com os modelos de Allison, apesar da ressalva de que mesmo uma decisão tomada em um desses "cenários ideais" não pode ser totalmente associada a um dos modelos do autor ${ }^{18}$ :

17 Goldstein (1999) utiliza o conceito de intensidade para se referir aos grupos de pressão que têm grande poder de influenciar uma decisão governamental. Quanto mais intenso o grupo, maior influência ele possuirá.

18 "Os modelos ideais nunca são encontrados em situaçôes reais de processos decisórios, que, muitas vezes, são definidos com base em variáveis que não são captadas por modelos que visam à simplificação teórica, como fatores emocionais, a preferência por uma burocracia em detrimento de outra, o simples hábito e outras" (Crabb e Holt 1989, 8). 


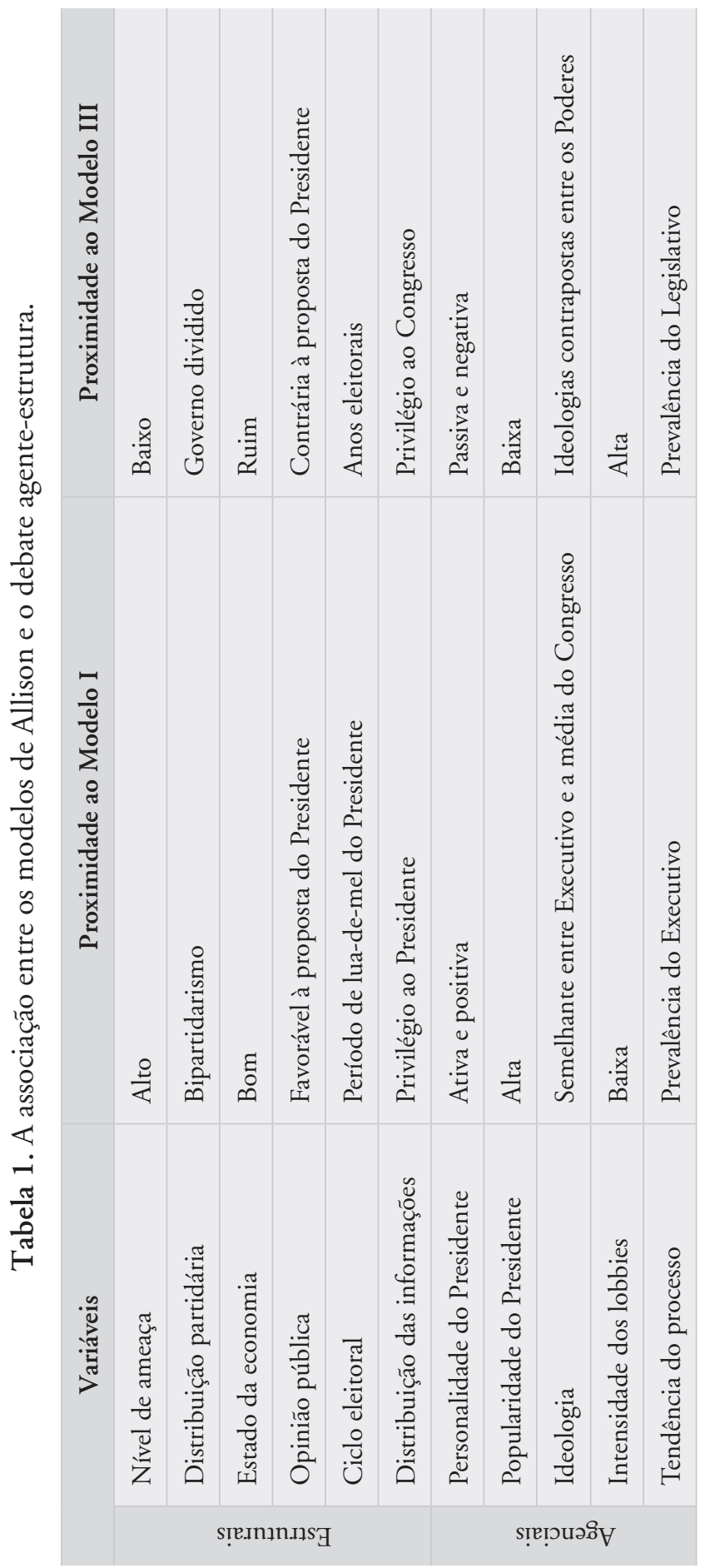


O quadro acima pode ser representado de modo mais simplificado em um gráfico (Figura 1) em que o eixo X representa a concentração de poder na estrutura doméstica e o eixo $\mathrm{Y}$ se refere à estrutura internacional.

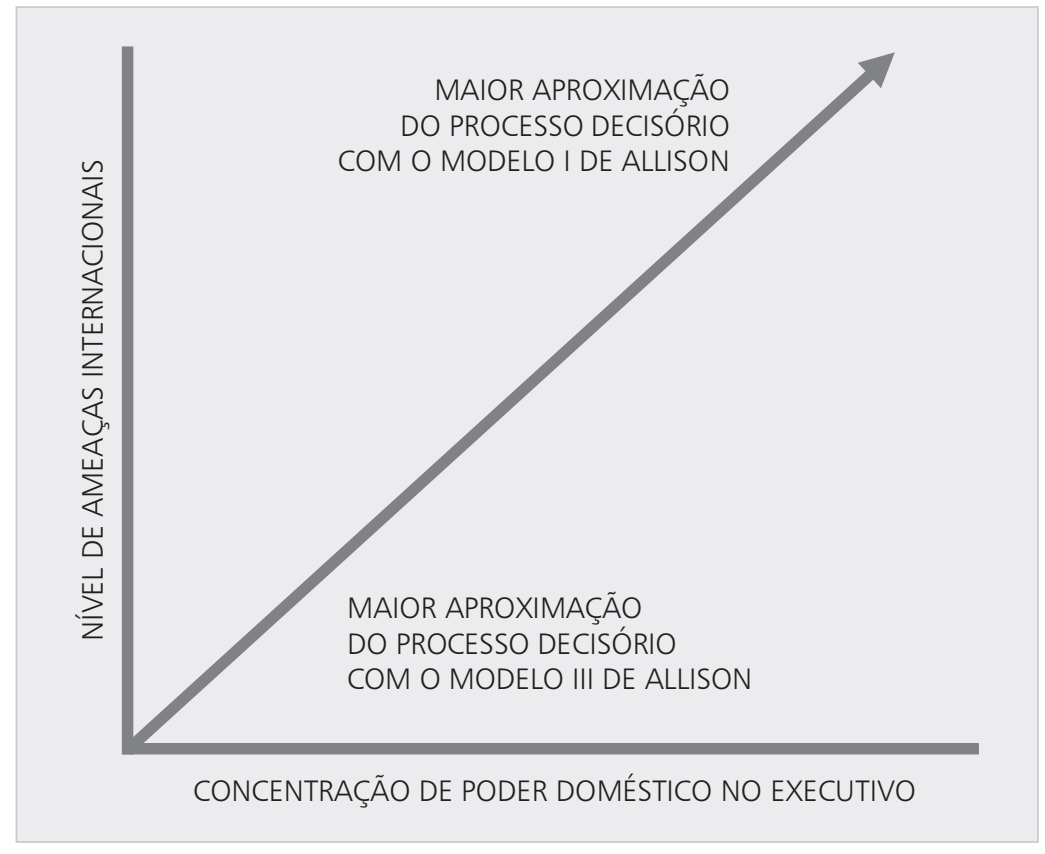

Figura 1. Continuum da concentração de poder decisório.

Como se nota, o aumento do nível de ameaças internacionais e da concentração do poder de decisão no Executivo leva a uma tomada de decisão que se aproxima do modelo I de Allison.

\section{Caracterização dos debates orçamentários durante as gestões Reagan e Bush}

Com base nas variáveis apresentadas, pode-se examinar os resultados dos processos orçamentários da primeira gestão de Reagan (1981-1984) e da Administração Bush (1989-1992). O primeiro promoveu grande elevação dos gastos militares e seu sucessor, ao contrário, objetivou realizar um profundo corte no orçamento de defesa, com o intuito de se adequar ao fim da corrida armamentista entre EUA e URSS.

Nos dois primeiros anos da Administração Reagan, diversos fatores contribuíram para que o Presidente pudesse elevar os gastos militares rapidamente. Havia uma clara ameaça internacional, que foi potencializada com a invasão soviética 
ao Afeganistão e a Revolução Islâmica do Irã. Tais acontecimentos ampliaram a percepção de ameaça pelos governantes e pela opinião pública ${ }^{19}$ estadunidense, o que facilitou a criação de um consenso bipartidário no Legislativo. Além disso, apesar de Barber (1992) analisar que Reagan era um Presidente passivo, diversos autores, como Stockman (1986) e Allison e Zelikow (1999, 276), definem-no como um Presidente de personalidade extremamente forte, que confrontava quaisquer possíveis obstáculos para fazer suas ideias prevalecerem, o que foi facilitado pela sua alta popularidade no início do mandato (Edwards III e Wayne 1994, 104) e grande capacidade de condução da mídia ${ }^{20}$.

Politicamente, Reagan encontrou condições de apoio raramente observadas em outros momentos históricos. Na eleição de 1980, recebeu 489 votos do Colégio Eleitoral, contra 49 de Jimmy Carter. O pleito também propiciou um grande nível de apoio ao Presidente no Congresso. Apesar de que a Câmara dos Representantes teria maioria do Partido Democrata, que elegeu 242 representantes contra 192 Republicanos, Reagan conseguiu um apoio bipartidário constante de Democratas conservadores do sul dos EUA, os denominados Boll Weevils, nas questôes do orçamento de defesa ${ }^{21}$.

$\mathrm{Na}$ economia, porém, a situação era bastante problemática, o que poderia significar uma redução do apoio do Congresso à sua proposta orçamentária. Mas, como o Partido Republicano havia vencido a eleição justamente por ter uma proposta orçamentária diferente da anterior, embasada no incentivo à economia do lado fornecedor (supply-side economics), que ficou popularmente conhecida como Reaganomics, o apoio a Reagan foi potencializado. Seu modelo passou a ser visto como uma possível solução para os problemas econômicos dos EUA.

A proposta tinha dois objetivos principais: diminuir o tamanho do Estado e os investimentos na área social, enquanto era maximizado o apoio aos grandes empresários, que seriam responsáveis por reerguer a economia estadunidense. Apesar dos grandes esforços para aplicar o novo modelo econômico, a Administração não conseguiu realizar as reduções que pretendia nos programas sociais, o que

19 Sobre a questão, é relevante a análise de Bartels (1991), que destaca que o amplo apoio da opinião pública, percentualmente, foi mais importante que outras variáveis, como a filiação partidária e a inclinação ideológica, para explicar o buildup de Reagan. Apesar das colocações do autor, porém, o modelo deste artigo pressupõe que a importância da opinião pública não é fixa, mas se altera de acordo com outras variáveis estruturais. Se Bartels (1991) estivesse totalmente correto com relação ao crescimento dos gastos durante o mandato de Reagan, a opinião pública teria a mesma importância em outros processos orçamentários, o que não ocorreu. Ao final do primeiro mandato de Reagan, por exemplo, o público deixou de apoiar o aumento dos gastos e, mesmo assim, o Presidente continuou solicitando mais recursos para a defesa (Stubbing e Mendel 1986).

20 Novamente, ressalta-se a visão da teoria elitista sobre a importância da mídia, que foi utilizada por Reagan como instrumento de convencimento da opinião pública.

21 Tal apoio se devia a dois fatores principais: ideologicamente, os Boll Weevils eram favoráveis ao estabelecimento de uma grande estrutura de defesa pelos EUA e, eleitoralmente, eram originários de distritos com grandes investimentos da indústria de defesa e, portanto, pró-Pentágono. 
gerou um déficit orçamentário recorde ${ }^{22}$, pois a ascensão dos gastos com defesa $\mathrm{a}^{23}$ foi mantida.

O buildup da defesa trouxe efeitos negativos também no longo prazo, pois o aumento dos gastos foi concentrado nas contas de "Pesquisa e Desenvolvimento" e "Aquisição de Novos Equipamentos", o que ocasionou os chamados efeitos de "onda de popa" e de "onda de proa" 24 . Isso comprometeu a capacidade de preparação do aparato de defesa dos EUA, já que o aumento nessas contas foi compensado pela redução nos gastos com "Manutenção" e "Treinamento de tropas" (Adams e Cain 1989; Steinbruner 1988, 147).

Enfim, Reagan encontrou um ambiente muito favorável ao aumento expressivo dos gastos militares e decidiu exercer uma ampla liderança no processo orçamentário.

George H. W. Bush, por outro lado, iniciou seu mandato precisando gerenciar ambientes muito diferentes, tanto internacional quanto domesticamente. A derrocada da União Soviética reduziu as ameaças evidentes aos EUA. Além disso, havia grandes preocupações com os altíssimos déficits orçamentários e com o grandioso comprometimento de gastos com defesa. Diante dessas condições estruturais, Bush propôs uma ampla redução das despesas militares, concentrando os cortes nas contas que Reagan havia priorizado. O Executivo requereu a redução

22 A partir dessa Administração, o déficit tornou-se um problema estrutural nos EUA. Como consequência desses déficits, a dívida dos EUA, entre 1980 e 1990, foi quadruplicada (Shuman 1992, 249). Apesar de que o déficit era um problema que já existia antes de Reagan, a multiplicação do déficit durante sua Administração, as mais altas taxas de desemprego desde a Grande Depressão e a forte recessão entre 1981 e 1982 foram decorrentes justamente de suas políticas orçamentárias, que poderiam ser evitadas (SHUMAN, 1992, p. 272). Além dessas consequências econômicas, a ineficiência do modelo orçamentário adotado por Reagan também trouxe efeitos políticos negativos. Em pouco tempo, o Congresso passou a ser menos favorável às suas políticas.

23 Esse desequilíbrio prejudicou o desempenho dos Republicanos na eleição de 1982. O Partido perdeu espaço na Câmara dos Representantes, que passou a ser composta por 267 Democratas e 165 Republicanos. Além disso, o apoio dos boll weevils ao Presidente também diminuiu. As decisōes bipartidárias, a partir de 1983, foram muito mais raras. Esse foi um ano em que "as motivações políticas estiveram acima das considerações sobre políticas" (CQA, 1984, p. 12). Por outro lado, a vantagem dos Republicanos no Senado foi minimamente ampliada: o partido passou a ter 54 Senadores, contra 46 dos Democratas. Importante destacar que as alteraçôes ideológicas em ambas as Casas foram muito mais profundas do que esses números demonstram. O Congresso eleito em 1982 era, ideologicamente, muito menos favorável a Reagan, obrigando-o a estabelecer negociaçōes mais duras com relação aos seus pedidos orçamentários.

24 A onda de popa se refere ao fato de que os compromissos com a pesquisa de novas tecnologias geram custos em diversos orçamentos posteriores, pois os recursos ficam comprometidos durante muitos anos para que o desenvolvimento não fique estagnado. O segundo efeito pode se tornar ainda mais prejudicial, pois quando é encerrada a fase de pesquisa e desenvolvimento e o equipamento está pronto para ser produzido, a "onda de proa" significa que um valor muito elevado de recursos será comprometido, independentemente de o gasto prever que o programa tenha poucos ou muitos equipamentos contratados. Esse fato advém de dois problemas: primeiramente, relaciona-se com a previsão subestimada dos custos do equipamento no início de sua pesquisa e desenvolvimento, uma prática muito comum nos EUA; em segundo lugar, como o custo unitário de um equipamento aumenta se menos unidades forem produzidas, há uma elevação do custo total de um programa mesmo que o número de armamentos contratados seja reduzido. 
ou o encerramento de dez dos principais programas militares ${ }^{25}$, que considerava desnecessários ou excessivamente custosos.

A decisão do Executivo, ao propor cortes profundos no orçamento de defesa, estava embasada na opiniāo de analistas que haviam feito parte da gestão Reagan ${ }^{26}$, que fundamentaram suas escolhas com base em uma lógica simples: poupar recursos na defesa, em um cenário internacional de diminuição das ameaças, permitiria aplicá-los no aprimoramento do desempenho macroeconômico do país, que ainda passava por uma severa crise. Além disso, os altos investimentos em defesa realizados durante a gestão de Reagan diminuíram a necessidade de gastos militares elevados nos anos seguintes. Apesar desses argumentos, o Presidente não conseguiu convencer o Congresso de que os empregos perdidos na indústria de defesa seriam compensados, com sobras, em outras áreas ${ }^{27}$.

Ao propor a redução nos investimentos, Bush percebeu que precisaria enfrentar um ambiente doméstico bastante desfavorável. $\mathrm{O}$ fim da Guerra Fria ocasionou duas alterações importantes para o cenário político estadunidense: o consenso bipartidário entre Executivo e Congresso tornou-se menos provável e o poder de decisão pendeu para o Legislativo, o que foi decorrente da menor popularidade do Presidente, do agravamento das crises econômicas e do próprio déficit orçamentário, entre outros fatores. A relação de Bush com o Congresso, enfim, foi muito mais difícil que a de Reagan.

A composição partidária do Legislativo também era prejudicial aos interesses de Bush. A aprovação de suas políticas somente poderia ser realizada por meio de amplas negociações com os Democratas, que possuíam 258 assentos (59,3\%) na Câmara dos Representantes, enquanto os Republicanos ocuparam somente 176 vagas $(40,5 \%)$. No Senado, a situação era semelhante, com os Democratas ocupando 55 dos 100 assentos. Decisóes que privilegiassem o posicionamento do Presidente, portanto, eram de difícil costura. Na segunda metade do mandato, a situação se agravou, com Bush perdendo mais nove assentos na Câmara e mais um no Senado. O fim da Guerra Fria eliminou o "guia de resposta rápida” (McCormick et al. 1997, 135) que incentivava o bipartidarismo.

25 O gasto com defesa já estava sendo reduzido, em menor medida, desde 1985, mas o Secretário de Defesa de Bush, Dick Cheney, decidiu acelerar os cortes em seus pedidos orçamentários ao Congresso em cerca de US\$ 180 bilhões de dólares de 1989 a 1994 (Korb 1989). Entre os programas mais importantes que Cheney decidiu encerrar estavam o caça F-14D e a aeronave de rotor giratório V-22 Osprey, mas essas tentativas de corte do Executivo pararam no Congresso, que não aceitou colocar em risco os lucros das empresas contratantes e, consequentemente, os empregos em seus distritos eleitorais.

26 Um desses analistas era Lawrence Korb, que passou a defender o corte nos gastos: "Com esforços apropriados, nossos líderes políticos poderiam cortar dezenas de bilhões nos gastos do Pentágono, liberando um dinheiro significativo para usos verdadeiramente importantes e para as pessoas que os apoiam. Mas aí aparecem as más notícias. A liderança política para essa tarefa não se materializou, apesar da clara necessidade de que a América aperte o cinto fiscal e aumente nossa segurança em muitas áreas” (KORB, 2005).

27 Quando Bush assumiu, em 1989, o número de empregos relacionados com a indústria de defesa era muito maior do que o existente em 1980, quando Reagan chegou ao poder. De 1976 a 1986, esse número dobrou (Gholz e Sapolsky 1999-2000, 9), o que foi decisivo para que as mudanças pretendidas por Bush, que significariam perdas nesse setor, fossem rejeitadas pelos congressistas. 
Essas condições trouxeram prejuízos ao Presidente, que, em questões de política externa, teve apoio bipartidário em somente 19\% das votaçôes mais importantes na Câmara. No Senado, apesar de que o apoio era maior, ainda era muito pequeno (29\%). Ambos os dados representam níveis historicamente baixos. A diferença entre os apoios dos partidos (Republicano contra Democrata) era de $35 \%$ na Câmara e 34\% no Senado, ou seja, o apoio dos Republicanos a Bush girava em torno de 67,5\%, enquanto o apoio dos Democratas representava 32,5\% ${ }^{28}$.

Mesmo diante dessas divisões partidárias, que facilitaram a ascensão do Congresso, dois fatores poderiam favorecer a aprovação das reduções propostas por Bush. Em primeiro lugar, a opinião pública estadunidense já não era mais favorável a um crescimento dos investimentos militares (Bartels 1991). Em segundo, o Presidente havia assumido em um momento de recuperação econômica, decorrente da melhora dos índices macroeconômicos na segunda gestão de Reagan. Em 1989, a economia estadunidense passava pelo seu sétimo ano seguido de crescimento, sem sinais de retorno da estagnação (Mann 1990, 295); os juros haviam baixado e continuaram diminuindo durante a década de 90; a inflação estava controlada e o desemprego decresceu, reduzindo o índice de miséria. $\mathrm{O}$ único problema que permaneceu se agravando, desde a gestão de Reagan, e que continuou afetando grandiosamente os debates orçamentários durante os anos de Bush, era o déficit, que batia recordes a cada ano.

A partir do segundo ano de seu mandato, porém, a condição favorável da economia rapidamente retrocedeu ${ }^{29}$ e o Presidente se mostrou incapaz de amenizar a grave crise em que os EUA estavam inseridos ${ }^{30}$.

Além da ineficiência da política econômica da Administração Bush, a personalidade e a ideologia dos agentes que participaram dos processos decisórios do orçamento de defesa não contribuíram para a definição de uma linha política clara. Ideologicamente, o Congresso, nos anos de Bush, era muito mais liberal que o Legislativo da gestão Reagan.

Como se observa, a falta de uma ameaça externa, a inexistência de um plano coerente para lidar com o orçamento de defesa, o governo dividido e a queda no desempenho econômico do país, a partir do primeiro ano de sua gestão, contribuíam para a ascensão do Legislativo no processo decisório. Além desse contexto negativo, deve-se considerar que as características dos agentes que participaram dos debates

28 Os dados apresentados neste parágrafo foram retirados de McCormick et al (1997, p. 139).

29 Em 1990, a taxa de crescimento da economia declinou e os aumentos da inflação e do desemprego elevaram o índice de miséria. O déficit público também aumentou bruscamente. Essa rápida piora das condições macroeconômicas foi um fator de agravamento das relaçōes com o Congresso, que passou a tentar se impor sobre o Presidente no processo decisório. O crescimento do desemprego e dos défícits potencializou a tendência de ascensão do Legislativo sobre o Executivo, o que já era provável diante de um cenário de queda das ameaças internacionais e de governo dividido e reduziu drasticamente a popularidade de Bush.

30 Essa incapacidade de Bush de intervir positivamente na economia levou os marqueteiros de Clinton, na campanha presidencial de 1992, a conceberem o bordão “é a economia, estúpido!” (Pecequilo 2003, 306), referindo-se ao fato de que Bush não conseguiu definir uma política satisfatória com relação ao ambiente doméstico, além de não redefinir o posicionamento internacional do país. 
orçamentários aumentavam a tendência de prevalência do Congresso. O Legislativo enfrentado por Bush era mais liberal que o dos anos Reagan; a popularidade pessoal do Presidente manteve-se baixa durante a maior parte da gestão ${ }^{31}$; e, finalmente, o Presidente, apesar de sua personalidade forte e pró-ativa, adotou uma postura conciliatória com relação ao Legislativo, cabendo somente ao seu Secretário de Defesa a condução de debates mais rígidos sobre o orçamento de defesa.

A Tabela 1, elaborada a partir de registros históricos do apoio médio anual de ambas as Casas do Congresso aos Presidentes Reagan e Bush, demonstra numericamente a queda na aprovação das políticas deste:

Tabela 1. Aprovação do conteúdo das políticas presidenciais no Congresso (em percentagem)

\begin{tabular}{|c|c|c|c|c|c|c|c|c|r|}
\hline \multicolumn{3}{|c|}{ Reagan } & \multicolumn{9}{c|}{ Bush } \\
\hline $\mathbf{8 1}$ & $\mathbf{8 2}$ & $\mathbf{8 3}$ & $\mathbf{8 4}$ & Média & $\mathbf{8 9}$ & $\mathbf{9 0}$ & $\mathbf{9 1}$ & $\mathbf{9 2}$ & Média \\
\hline 82,4 & 72,4 & 67,1 & 65,8 & 71,9 & 62,6 & 46,8 & 54,2 & 43 & 52,2 \\
\hline
\end{tabular}

Fonte: tabela elaborada pelo autor com base nos dados descritos no CQA (1993, p. 9-B).

Como se observa, apesar de o efeito de lua-de-mel entre Bush e o Congresso ter sido importante nos dois primeiros anos após as eleiçóes (presidenciais e de meio-termo), a média de Bush, se comparada a de seu antecessor, é muito baixa $(19,7 \%$ menor). Mesmo no ano em que Bush teve o maior apoio no Congresso, em 1989 (62,6\%), o índice foi inferior ao mais baixo apoio do primeiro mandato de Reagan (65,8\%). Nos anos de 1990 e 1992, os índices de apoio a Bush no Congresso foram historicamente baixos (CQA 1991, 22). O Presidente, enfim, obteve a pior média de aprovação desde 1953, quando o índice começou a ser medido. Na Câmara, em 1990, Bush perdeu em cerca de 7 a cada 10 votaçóes. Além disso, outra característica interessante da análise das votações em 1990, que pode estar associada às pressões eleitorais, foi a grande divisão partidária dos votos, que representou um recorde histórico de diferença no posicionamento dos partidos (CQA 1991, 32). Mann (1990, 294) considera que "o histórico legislativo do Presidente Bush no Congresso era medíocre".

Nessa conjuntura, a redução dos gastos com defesa, que deveria ser natural (na visão das teorias sistêmicas), não ocorreu. Isso está relacionado, principalmente, com as características estruturais enfrentadas pela Administração Bush e com o pouco comprometimento dos agentes que participaram do processo decisório com esse objetivo.

31 A exceção foi o período da campanha militar no Kuwait, em que o apoio a Bush cresceu significativamente. 


\section{Breve comparação entre os orçamentos de defesa dos anos Reagan e George H. W. Bush}

O exame das diferenças estruturais e agenciais entre as gestôes Reagan e Bush indica que os Presidentes governaram em realidades muito diferentes e as enfrentaram por meio de visões distintas. A comparação ${ }^{32}$ entre os resultados orçamentários obtidos por ambos pode ser realizada, mesmo que de modo breve, de três diferentes formas, que demonstram que os processos decisórios dessas gestôes se aproximam de extremos opostos do continuum de distribuição de poder proposto neste artigo.

Primeiramente, serão analisadas as discussões orçamentárias da Administração Reagan e, posteriormente, os dados da gestão Bush.

A primeira maneira de examinar os níveis de aprovação das propostas orçamentárias do Presidente pelo Congresso é comparar os valores absolutos de gastos com defesa requeridos pelo Executivo com as quantias finais aprovadas pelo Legislativo (Tabela 2).

Tabela 2. Percentual de aprovação dos pedidos orçamentários de Reagan para apropriações com defesa (valores totais ${ }^{33}$ ).

\begin{tabular}{|c|c|c|c|c|c|}
\hline & $\begin{array}{c}\text { Requerimento da } \\
\text { Administração }\end{array}$ & $\begin{array}{c}\text { Valor aprovado } \\
\text { pela Casa }\end{array}$ & $\begin{array}{c}\text { Valor aprovado } \\
\text { pelo Senado }\end{array}$ & $\begin{array}{c}\text { Valor final } \\
\text { aprovado }\end{array}$ & $\begin{array}{c}\text { Índice de } \\
\text { aprovação }\end{array}$ \\
\hline 1981 & 200.878 .234 & 197.517 .189 & 208.868 .645 & 199.899 .264 & $99,51 \%$ \\
\hline 1982 & 249.612 .409 & 230.750 .564 & 233.749 .005 & 232.026 .724 & $92,95 \%$ \\
\hline 1983 & 260.926 .119 & 247.062 .791 & 253.945 .137 & 249.820 .875 & $95,74 \%$ \\
\hline 1984 & 292.221 .823 & 270.063 .432 & 279.392 .105 & 274.398 .173 & $93,90 \%$ \\
\hline
\end{tabular}

Fonte: tabela elaborada com base nos dados do Congressional Quarterly Almanac (1982, p. 321; 1983, p. 278; 1984, p. 481; 1985, p. 400).

Como se observa, o Congresso, mesmo nos anos em que houve um aprofundamento da recessão econômica nos EUA, manteve forte apoio às demandas de Reagan. O simples exame desses números, porém, não demonstra claramente o nível de prevalência do Executivo sobre o Legislativo.

A análise precisa ser aprofundada por meio da observação das discussóes de cunho mais geral sobre os programas de armamentos realizadas anualmente

32 A comparação, a princípio, pode parecer desigual, pois a tendência institucional do Congresso é ter sérias ressalvas (principalmente por critérios políticos) à redução de custos com defesa. A questão, porém, não é tão simples. O Legislativo, em outros períodos históricos, como no segundo mandato de Reagan, forçou a redução dos gastos militares, respondendo ao aumento excessivo dos déficits orçamentários, que passaram a pressionar os congressistas.

33 Em milhares de dólares. 
durante a gestão. Os orçamentos aprovados em 1981 e 1982 foram amplamente favoráveis às propostas do Executivo não somente em termos financeiros, mas também com relação aos programas aprovados. Todos os armamentos e sistemas concebidos pelas Forças Armadas e defendidos por Reagan foram aceitos pelo Legislativo nesses anos.

Nos dois últimos anos da gestão, porém, a situação foi levemente alterada. $\mathrm{O}$ apoio da opiniāo pública ao Presidente caiu, principalmente pelo aumento dos déficits orçamentários e pela piora de diversos índices macroeconômicos. A consequência dessas alterações foi sentida na eleição de meio-termo de 1982, quando o Partido Republicano perdeu muito espaço no Legislativo. A partir de então, as negociaçôes orçamentárias passaram a ser mais difíceis para Reagan, que, mesmo assim, continuou obtendo ampla margem de aprovação para seu projeto de buildup militar. Mesmo no quarto ano de gestão, apesar de alguns programas terem sido desacelerados, nenhum deles foi encerrado pelos legisladores.

Por fim, também é possível observar os níveis de aprovação das propostas de Reagan pelo Congresso pelo exame das discussóes sobre programas de armamentos específicos propostos pelo Executivo nos quatro anos da Administração. Três deles geraram grandes polêmicas entre Executivo e Legislativo no período e, assim mesmo, receberam investimentos vultosos: os mísseis $\mathrm{M}-\mathrm{X}^{34}$, o bombardeiro B-1 ${ }^{35}$ e o programa da Marinha de 600 Navios. A análise aprofundada desses programas demonstra que, apesar de terem sofrido alguns cortes em anos específicos, todos foram amplamente aprovados pelo Congresso.

As três observações demonstram que Reagan foi amplamente atendido pelo Legislativo, o que indica que as características desses processos os aproximam das tendências previstas pelo modelo racional de Allison. O Presidente, teoricamente, representa uma grande parcela da população do país e, estando mais distante das pressões específicas dos grupos de interesse, tem mais condiçôes de aproximar suas demandas do interesse nacional.

Por outro lado, se os mesmos critérios forem adotados para analisar os processos decisórios do orçamento de defesa da gestão Bush, resultados muito diferentes serão obtidos.

Os índices de aprovação dos requerimentos de Bush pelo Congresso levam a pressupor que o desempenho desse Presidente foi bastante positivo, mesmo se comparado ao de Reagan, como se pode observar pela Tabela 3.

34 Programa de mísseis estratégicos bastante controverso, pois contrariava os acordos de desarmamento negociados bilateralmente com a URSS.

35 Bombardeiro que objetivava a substituição do B-52, utilizado desde a Segunda Guerra Mundial. 
Tabela 3. Percentual de aprovação dos pedidos orçamentários de Bush para apropriações com defesa (valores totais ${ }^{36}$ ):

\begin{tabular}{|l|c|c|c|c|c|}
\hline & $\begin{array}{c}\text { Requerimento da } \\
\text { Administração }\end{array}$ & $\begin{array}{c}\text { Valor aprovado } \\
\text { pela Casa }\end{array}$ & $\begin{array}{c}\text { Valor Aprovado } \\
\text { pelo Senado }\end{array}$ & $\begin{array}{c}\text { Valor final } \\
\text { aprovado }\end{array}$ & $\begin{array}{c}\text { Índice de } \\
\text { aprovação }\end{array}$ \\
\hline FY1990 & $223.516,2$ & $226.048,3$ & $223.369,2$ & $302.963,7$ & $100 \%{ }^{37}$ \\
\hline FY1991 & $288.641,7$ & $269.281,4$ & $268.240,9$ & $269.981,5$ & $93,54 \%$ \\
\hline FY1992 & $270.936,3$ & $270.565,8$ & $270.257,7$ & $269.911,2$ & $99,62 \%$ \\
\hline FY1993 & $261.133,5$ & $251.866,7$ & $250.685,6$ & $253.786,6$ & $97,19 \%$ \\
\hline
\end{tabular}

Fonte: tabela elaborada com base nos dados do CQA (1990, p. 452; 1991, p. 813; 1992, p. 622; 1993, p. 599)

O nível de apoio que a tabela ilustra é maior que o de Reagan em seu primeiro mandato. Novamente, porém, os dados devem ser qualificados, a partir da observação mais específica das discussões orçamentárias.

Primeiramente, é importante observar que o valor da última aprovação do Congresso (aproximadamente US\$253,8 bilhões) é maior que o primeiro requerimento orçamentário da Administração Bush (aproximadamente US\$ 223, 5 bilhôes). Isso demonstra que a estratégia do Legislativo para evitar reduções drásticas dos gastos militares durante os quatro anos da gestão foi bastante agressiva. No primeiro ano, os congressistas garantiram a manutenção dos programas politicamente importantes, mesmo diante das propostas de corte ou encerramento enviadas por Bush e Cheney. Com isso, nos três anos seguintes, o trabalho do Congresso se resumiu a continuar apropriando os valores requeridos pelo Presidente em sua totalidade, além de incluir valores adicionais.

A análise dos debates orçamentários realizados anualmente (CQA 1990; 1991; 1992; 1993) demonstra que, já nos primeiros anos de gestão, as divergências entre os orçamentos propostos pelo Executivo e as versōes finais aprovadas pelo Legislativo eram profundas. Desde sua posse, Bush defendeu que os EUA deveriam concentrar os gastos em armamentos estratégicos, realizando cortes mais profundos em programas convencionais ${ }^{1}$, pois muitos se mostravam ineficientes. Apesar dos esforços do Executivo, o Congresso decidiu manter todos os programas, independentemente da realização de uma análise profunda sobre a sua eficiência.

36 Em milhōes de dólares.

37 O valor utilizado na tabela leva a crer que a totalidade do pedido orçamentário de Bush foi aprovado pelo Congresso. Deve-se levar em consideração, porém, que o orçamento do Congresso foi muito diferente do presidencial. O valor aprovado pelos legisladores foi $35,5 \%$ maior que o requerido pelo Presidente. Esse aumento foi concentrado em gastos com pessoal terceirizado, para os quais Bush não havia solicitado quaisquer valores, prevendo incluí-los em outra conta orçamentária. Além disso, também era composto por um aumento de mais de US\$ 6 bilhōes na conta de pesquisa e desenvolvimento, relativo a programas que o Presidente pretendia cortar e que foram mantidos pelo Legislativo. 
O único argumento para a manutenção era a importância política dos empregos gerados pelo investimento nesses equipamentos.

Nos três anos seguintes, a lógica se manteve. O Executivo propôs o corte de diversos programas convencionais e o Congresso os manteve, minimizando o ritmo de redução de gastos. Nos programas mais controversos, a velocidade dos gastos foi atenuada, mas nenhum programa foi cortado nos quatro anos de gestão, havendo a manutenção dos efeitos de "onda de popa" e "onda de proa" gerados pela Administração Reagan.

Entre os programas mais custosos que foram discutidos durante o governo Bush, estavam o bombardeiro B-2 Stealth, os mísseis M-X e o programa de reaparelhamento da Marinha. Bush propôs o encerramento dos dois primeiros e a redução dos investimentos no terceiro, pois entendia que nenhum deles era essencial para a defesa dos EUA. O único que foi cancelado, apesar da forte contrariedade dos legisladores, foi o MX. Essa decisão não estava relacionada com as preferências dos legisladores, mas decorreu da assinatura dos acordos START entre EUA e URSS, que decretaram o fim dos investimentos nos mísseis.

Se forem comparados os requerimentos orçamentários de Bush com os valores aprovados pelo Congresso, há, claramente, uma prevalência da política sobre a racionalização dos gastos, com destaque para a manutenção de programas de armamentos que eram considerados inadequados pelo Executivo ${ }^{38}$. A manutenção desses programas impôs uma grande pressão sobre os investimentos de longo prazo, sem que houvesse uma ampla discussão acerca da eficiência ou necessidade dos equipamentos. Antes da Guerra Fria, os EUA se desmobilizavam no fim de suas guerras, mas isso não aconteceu, pela primeira vez, depois do declínio da URSS (Gholz e Sapolski 1999-2000, 7). A partir de então, mesmo em um ambiente de poucas ameaças à sobrevivência do país, as aquisiçôes da defesa passaram a ser dominadas por incentivos clientelistas (Gholz e Sapolski 1999-2000, 22).

Motivar politicamente as decisões do orçamento de defesa não era uma prática nova, mas sua importância aumentou muito a partir dos anos 1990. Nesse período, o Triângulo de Ferro da defesa passou a dominar as discussōes orçamentárias (Lindsay 1991). A ascensão do Congresso, durante a gestão Bush, tornou a elaboração e a especificação dos gastos em defesa uma decisão muito mais complexa, que passou a estar mais próxima da lógica do modelo III (política governamental) de Allison.

38 O Congresso optou por manter todos os programas politicamente importantes. Um dos exemplos mais notórios de como a política prevaleceu foi a aeronave V-22 Osprey, que era produzida em 45 estados dos EUA, por mais de 2000 empresas contratadas e subcontratadas (GAILLARD, 2006; JONES, 2004). A análise de como essas empresas, seus lobistas e os militares procuraram pressionar os legisladores para que o programa fosse mantido ilustra com muita precisão como interesses específicos e embasados em conexões eleitorais prevalecem, mesmo em momentos de dificuldades econômicas, sobre a racionalidade objetiva no processo orçamentário estadunidense. 


\section{Conclusões}

Ao cotejar teses sistêmicas, os modelos conceituais de Graham Allison e os conceitos do debate agente-estrutura, este artigo examinou o processo de elaboração do orçamento de defesa dos EUA em duas gestōes que apresentaram características muito distintas.

O objetivo foi apontar o elevado grau de complexidade das discussões orçamentárias sobre a defesa estadunidense, mais do que esmiuçar essas questóes com o nível de profundidade que o tema mereceria. Apesar disso, as observaçóes realizadas podem demonstrar que o Executivo, durante os primeiros anos da Administração Reagan, tinha prevalência no processo decisório, o que levou à tendência de aprovação de suas demandas pelo Legislativo e à criação de políticas que se aproximaram mais do modelo I de Allison, apesar de que o conceito de racionalidade do autor não se encaixa perfeitamente na explicação desses processos decisórios.

Ao contrário, os orçamentos construídos durante a gestão Bush se aproximaram do modelo III de Allison, pois a emergência do Congresso, que retomou sua margem de manobra na discussão orçamentária naquela Administração, impediu o cancelamento de programas de armamentos que o Presidente considerava inadequados ao atendimento do interesse nacional dos EUA por interesses meramente político-eleitorais. A decisão final dos processos foi mais fortemente influenciada pelos lobbies das indústrias de defesa, cujo comportamento não foi examinado detidamente neste artigo.

Tanto o ambiente internacional quanto o doméstico foram decisivos para que os processos decisórios sofressem alteraçōes. A análise evidencia que, independentemente das características específicas que apresentam os processos decisórios, em todos houve pressões muito fortes pela continuidade de gastos militares elevados. Essa lógica, que está relacionada tanto com a estrutura quanto com a característica dos agentes que participaram das discussões orçamentárias nos EUA, impediu uma redução efetiva dos gastos com defesa estadunidense que produzisse efeitos de longo prazo.

O atual Presidente daquele país, Barack Obama, vem tendo sérias dificuldades em seus esforços de reduzir o orçamento de defesa. A conjuntura atual é muito semelhante à enfrentada por Bush e, por isso, pode-se pressupor que dificilmente os cortes nos gastos de defesa que vem sendo observados atualmente produzam consequências duradouras. Novamente, há diversas reduções nas contas de pesquisa e desenvolvimento que não estão relacionadas com o cancelamento de programas, mas apenas com seu adiamento. No futuro, é provável a manutenção dos efeitos de onda de proa e de onda de popa, que provocarão uma nova curva ascendente dos gastos. 


\section{Referências bibliográficas}

ADAMS, G.; CAIN, S. A. (1989) Defense Dilemmas in the 1990s. International Security, Vol. 13, n 4, 1989, p. 5-15.

ALliSON, G. T. (1969) Conceptual Models and the Cuban Missile Crisis. The American Political Science Review, Vol. 63, n³ 1969, p. 689-718.

ALLISON, G. T.; ZELIKOW, P. (1999) Essence of Decision: Explaining the Cuban Missile Crisis. New York: Longman, 416 p.

ANDRADE, L.; YOUNG, G. (1996) Presidential Agenda Setting: influences on the emphasis of foreign policy. Political Research, Vol. 49, n³ 3, 1996, p. 591-605.

BARBER, J. D. (1992) The Presidential Character: predicting performance in the White House. 4 ed. EUA: Pearson, 544 p.

BARRETT, A. W.; ESHBAUGH-SOHA, M. (2007) Presidential Success on the Substance of Legislation. Political Research Quarterly, Vol. 60, n 1, 2007, p. 100-112.

BARTELS, L. M. (1991) Constituency Opinion and Congressional Policy Making: the Reagan defense build up. The American Political Science Review, Vol. 85, n² 2, 1991, p. 457-474.

BAUM, M. A. (2002) The Constituent Foundations of the Rally-Round-the-Flag Phenomenon. International Studies Quarterly, Vol. 46, n² 2, 2002, p. 263-298.

BERNSTEIN, B. J. (2000) Understanding Decisionmaking, U.S. Foreign Policy, and the Cuban Missile Crisis: a review essay. International Security, Vol. 25, n 1, 2000, p. 134-164.

BERRY; W. D.; LOWERY, D. (1990) An Alternative Approach to Understanding Budgetary Trade-offs. American Journal of Political Science, Vol. 34, n 3, 1990, p. 671-705.

COBB, S. A. (1969) Defense Spending and Foreign Policy in the House of Representatives. The Journal of Conflict Resolution, Vol. 13, $\mathrm{n}^{\circ} 3$, 1969, p. 358-369.

CQA - CONGRESSIONAL QUARTERLY ALMANAC. (1982) 97th Congress. 1st Session, 1981. Vol. XXXVII. Washington: Congressional Quarterly Inc.

. (1983) 97th Congress. 2nd Session, 1982. Vol. XXXVIII. Washington: Congressional Quarterly Inc.

Quarterly Inc.

(1984) 98th Congress. 1st Session, 1983. Vol. XXXIX. Washington: Congressional

. (1985) 98th Congress. 2nd Session, 1984. Vol. XXXVIII. Washington: Congressional Quarterly Inc.

(1990) 101st Congress. 1st Session, 1989. Vol. XLV. Washington: Congressional Quarterly Inc.

(1991) 101st Congress. 2nd Session, 1990. Vol. XLVI. Washington: Congressional Quarterly Inc. 
(1992) 102nd Congress. 1st Session, 1991. Vol. XLVII. Washington: Congressional Quarterly Inc.

(1993) 102nd Congress. 2nd Session, 1992. Vol. XLVIII. Washington: Congressional Quarterly Inc.

CRABB, Jr., C. V. HOLT, P. M. (1989) Invitation to Struggle: Congress, the President, and Foreign Policy. 3rd ed. EUA: Congressional Quarterly Press, 267 p.

DOMKE, W. K. (1984) Waste, Weapons, and Resolve: defense posture and politics in the defense budget. Policy Sciences, Vol. 16, n 4, 1984, p. 371-390.

EDWARDS III, G. C.; WAYNE, S. J. (1994) Presidential Leadership: politics and policy making. 3rd ed. EUA: Ed. St. Martins, 624 p.

GAILLARD, L. (2006) V-22: Wonder weapon or Widow Maker? They warned us. But no one is listening. Center For Defense Information, publicado em: [www.cdi.org/pdfs/gailliard\%20 on\%20v-22.pdf]. Disponibilidade: 10/12/2010.

GHOLZ, E.; SAPOLSKY, H. M. (1999-2000) Reestructuring the U.S. Defense Industry. International Security, Vol. 24, n 3, 1999-2000, p. 5-51.

GOLDSTEIN, K. M. (1999) Interest Groups, Lobbying, and Participation in America. EUA: Cambridge University Press, 172 p.

JENTLESON, B. W. (2010) American Foreign Policy: the dynamics of choice in the $21^{\text {st }}$ century. 4 ed. EUA: Norton, 719 p.

JONES, C. M. (2004) Roles, Politics, and the Survival of the V-22 Osprey. In. WITTKOPF, E. R.; McCORMICK, J. M. The Domestic Sources of American Foreign Policy: insights and evidence. 4 ed. EUA: Rowman and Littlefield Publishers, p. 283-301.

KORB, L. (2005) Americans: cut Pentagon spending. San Diego Union Tribune, 18 mar. 2005, publicado em [http://www.cdi.org/friendlyversion/printversion.cfm?documentID=2935]. Disponibilidade: 19/02/2009.

(1989) How to Reduce Military Spending. New York Times, 21 Nov. 1989, publicado em [http://www.nytimes.com/1989/11/21/opinion/how-to-reduce-military-spending. html?scp=23\&sq=V-22+Osprey\&st=nyt]. Disponibilidade: 11/01/2010.

KRAUTHAMMER, C. (1990/1991) The Unipolar Moment. Foreign Affairs, Vol. 70, nº 1, 1990/1991, p. 23-33.

LINDSAY, J. M. (1991) Testing the Parochial Hypothesis: Congress and the Strategic Defense Initiative. The Journal of Politics, Vol. 53, $\mathrm{n}^{\circ} 3,1991$, p. 860-876.

MAYER, K. R. (1995) Electoral Cycles in Federal Government Prime Contract Awards: StatLevel Evidence from 1988 and 1992 Presidential Elections. American Journal of Political Science, Vol. 39, $\mathrm{n}^{\circ} 1,1995$, p. 162-185.

MAYHEW, D. R. (1991) Divided we govern: party control, lawmaking, and investigations, 19461990. New Haven and London: Yale University Press, 192 p. 
MCCORMICK, J. M.; WITTKOPF, E. R. (1990) Bipartisanship, Partisanship, and Ideology in Congressional-Executive Foreign Policy Relations, 1947-1988. The Journal of Politics, Vol. 52, n 4, 1990, p. 1077-1100.

MCCORMICK, J. M.; WITTKOPF, E. R.; DANNA, D. M. (1997) Politics and Bipartisanship at the Water's Edge: a note on Bush and Clinton. Polity, Vol. 30, n 1, 1997, p. 133-149.

MILNER, H. V. (1997) Interests, Institutions, and Information: Domestic Politics and International Relations. New Jersey: Princeton University Press, 328 p.

OLSON, M. (1999) A Lógica da Ação Coletiva: os benefícios públicos e uma teoria dos grupos sociais. São Paulo: Edusp, 201 p.

ONEAL, J. R.; BRYAN, A. L. (1995) The Rally 'Round the Flag Effect in U.S. Foreign Policy Crises, 1950-1985. Political Behavior, Vol. 17, n 4, 1995, p. 379-401.

SHEPSLE, K. A.; WEINGAST, B. R. (1984) Legislative Politics and Budget Outcomes. In. MILLS, G. B.; PALMER, J. L. , Ed. Federal Budget Policy in the 1980s. Washington: The Urban Institute Press, 468 p.

SMITH, H. (1996) The Power Game: How Washington Works. EUA: Ballantine Books, 793 p. STEINBRUNER, J. D. (1988) Restructuring American foreign policy. EUA: Brookings Institution, $200 \mathrm{p}$.

STOCKMAN, D. A. (1986) The Triumph of Politics: Why The Reagan Revolution Failed. EUA: Harper \& Row, 422 p.

STRANGE, S. (1999) States and Markets. 2 ed. EUA: Continuum, 280 p.

STUBBING, R. A. (1984) The Defense Budget. In. MILLS, G. B.; PALMER, J. L. (ed.) Federal Budget Policy in the 1980s. Washington: The Urban Institute Press, 468 p.

STUBBING, R. A.; MENDEL, R. A. (1986) The Defense Game: An insider explores the astonishing realities of America's defense establishment. EUA: Harper \& Row, 445 p.

THRALL, A. T.; J. K. CRAMER. (2009) American Foreign Policy and the Politics of Fear: threat inflation since 9/11. New York: Routledge, 256 p.

WALTZ, K. N. (2002) Teoria das Relações Internacionais. Lisboa: Gradiva, 344 p.

WIGHT, C. (2006) Agents, Structures and International Relations: politics as ontology. New York: Cambridge University Press, 306 p.

WITTKOPF, E.; MCCORMICK, J. M. (1998) Congress, the President, and the End of the Cold War: has anything changed? The Journal of Conflict Resolution, Vol. 42, $\mathrm{n}^{\circ} 4,1998$, p. $440-466$.

(2004) The Domestic Sources of American Foreign Policy: insights and evidence. 4 ed. EUA: Rowman and Littlefield Publishers, 416 p.

Recebido em 15 de maio de 2014 Aceito em 2 de setembro de 2014 


\section{Resumo}

Ao longo das últimas décadas, gastos substanciais com defesa têm sido mantidos pelos EUA. Essas despesas simbolizam uma reação do país a condições sistêmicas, mas também se relacionam com os interesses de agentes domésticos que trabalham para sua manutenção. Neste artigo, pretende-se examinar como funcionou a combinação dessas pressões no período que marcou o fim da Guerra-Fria, por meio da comparação entre os orçamentos de defesa da primeira gestão de Reagan (1981-1984) e da Administração Bush (1989-1992).

Palavras-chave: George H. W. Bush; orçamento de Defesa dos EUA; Ronald Reagan.

\section{Abstract}

Throughout the last decades, great amounts of money have been spent in defense by the United States. This spending symbolizes the country's reaction to systemic conditions but it is also related to the interests of domestic agents that pressure for their maintenance. In this article, we seek to examine how the combination of these pressures have worked during the end of the Cold War period by comparing the defense budgets of the first Reagan Administration (1981-1984) with the Bush Administration (1989-1992) ones.

Keywords: George H. W. Bush; American Defense budget; Ronald Reagan. 